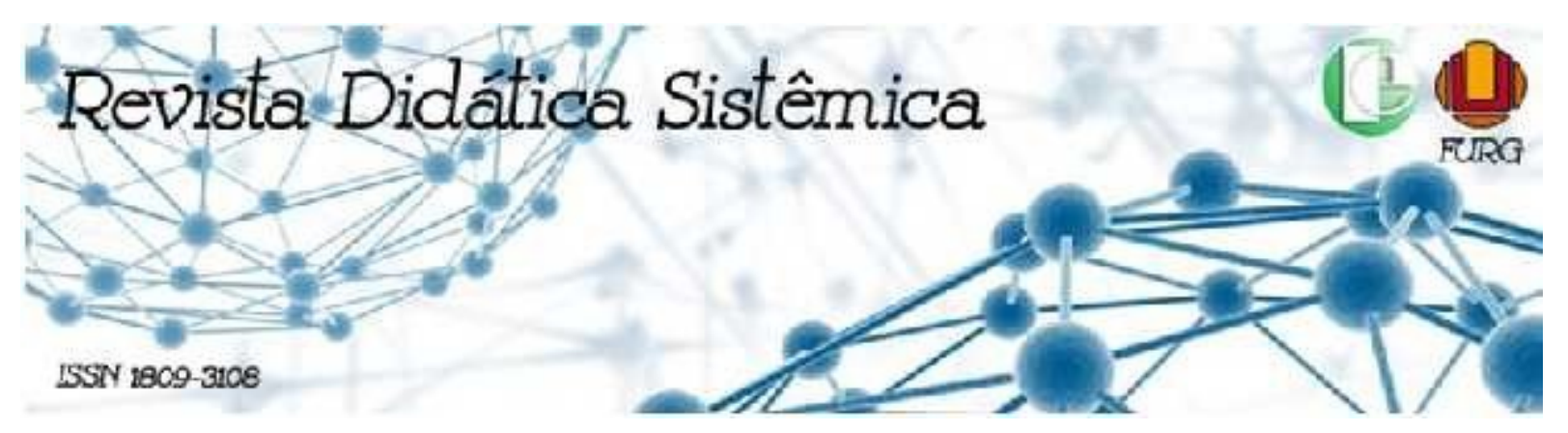

\title{
USOS E APROPRIAÇÕES DAS DANÇAS POPULARES NA EDUCAÇÃO INFANTIL DE VITÓRIA/ES
}

\author{
Érica Bolzan ${ }^{1}$ \\ Rodrigo Lema Del Rio Martins ${ }^{2}$ \\ André da Silva Mello
}

\begin{abstract}
RESUMO
Analisa os usos e as apropriações que os dinamizadores de Artes e Educação Física fazem das danças populares na Educação Infantil, de Vitória/ES. Utiliza o método descritivo-interpretativo, com a aplicação de questionários para 24 docentes que atuam nos Centros Municipais de Educação Infantil (CMEIs). Os resultados apontam que os dinamizadores fazem diferentes usos dessas danças em seus cotidianos, em estreita articulação com os projetos institucionais dos CMEIs. Contudo, são poucas as mediações que valorizam as agências das crianças, pois as danças populares estão mais presentes nos momentos de apresentações do que ao longo do ano letivo. Dentre os fatores que dificultam o trabalho com as danças populares, sobressai a questão da religiosidade, pela crença de que a prática dessas manifestações evoca a devoção. Conclui-se que as danças populares se apresentam como conhecimentos potentes para tematizações e reflexões sobre as questões étnico-raciais nas instituições infantis.
\end{abstract}

Palavras-chave: Danças populares. Educação Infantil. Usos e apropriações.

\section{FOLK DANCES USES AND APPROPRIATIONS IN CHILDREN'S EDUCATION IN VITÓRIA/ES}

Abstract: The work analyzes the uses and appropriations, in which the Arts and Physical Education facilitators make out of folk dances in Children 's Education held in the city of Vitória/ES. It uses the

\footnotetext{
${ }^{1}$ Profa. do Instituto Federal de Educação, Ciência e Tecnologia Baiano (IF Baiano). Membro do Núcleo de Aprendizagens com as Infâncias e seus Fazeres (NAIF), ericabolzan@yahoo.com.br.

${ }^{2}$ Prof. Adjunto da Universidade Federal Rural do Rio de Janeiro (UFRRJ). Vice-líder do Núcleo de Aprendizagens com as Infâncias e seus Fazeres (NAIF), rodrigodrmartins@ufrrj.br.

${ }^{3}$ Prof. Associado da Universidade Federal do Espírito Santo (UFES). Líder do Núcleo de Aprendizagens com as Infâncias e seus Fazeres (NAIF), andremellovix@gmail.com.
} 
descriptive-interpretative method, with the application of a questionnaire for 24 teachers working at Children 's Education Municipal Centers (CMEIs). Results indicate that the facilitators daily make different uses of such dances, in a narrow articulation with the CMEIs' institutional projects. However, there aren't many mediations that value the children 's agencies, since folk dances are more present during the presentations moments than throughout the school year. Among all the factors that hinder the work with folk dances, it is highlighted the religion matter, through the belief that the practice of those manifestations evokes devotion. In conclusion, folk dances are presented as strong knowledge for the creation of topics and reflections regarding the ethinic-racial issues in children's institutions.

Keywords: Folk dances. Children 's education. Uses and appropriations.

\title{
USOS Y APROPIACIONES DE BAILES POPULARES EN EDUCACIÓN INFANTIL EN VITÓRIA/ES
}

\begin{abstract}
RESUMEN
Analiza los usos y apropiaciones que los dinamizadores de las Artes y la Educación Física hacen de los bailes populares en Educación Infantil en Vitória/ES. Utiliza el método descriptivo-interpretativo, con la aplicación de cuestionarios para 24 docentes que laboran en los Centros Municipales de Educación Infantil (CMEIs). Los resultados muestran que los dinamizadores hacen diferentes usos de estos bailes en su vida diaria, en estrecha articulación con los proyectos institucionales de las CMEIs. Sin embargo, son pocas las mediaciones que valoran las agencias infantiles, ya que los bailes populares están más presentes en los momentos de presentaciones que durante el año escolar. Entre los factores que dificultan el trabajo con danzas populares, se destaca el tema de la religiosidad, debido a la creencia de que la práctica de estas manifestaciones evoca devoción. Concluimos que las danzas populares se presentan como un potente conocimiento para tematizaciones y reflexiones sobre temas étnico-raciales en las instituciones infantiles.
\end{abstract}

Palabras clave: Bailes populares. Educación Infantil. Usos y apropiaciones.

\section{INTRODUÇÃO}

A dança é uma das mais antigas formas de expressão humana, materializada nas manifestações artísticas, culturais e corporais praticadas ao longo da história. Como conhecimento, tem adentrado os currículos escolares, acompanhada, desde os anos finais da década 1990, por um intenso movimento de propostas curriculares, pedagógicas e artísticas para seu ensino, em abordagens mais e menos sistematizadas e estruturadas para os componentes curriculares (GEHRES, 2020).

No âmbito das danças populares, embora seja um tema ainda incipiente na Educação Infantil (EI), identificamos autores e autoras do campo da Educação Física (EF) que têm discutido seus aspectos teóricos e conceituais (BRASILEIRO, 2010), apresentando propostas de mediação com foco no ensino fundamental, sobretudo, em suas séries finais (DINIZ; 
DARIDO, 2015) e/ou abordando a formação de professores para o seu ensino na escola (BRASILEIRO, 2010; DINIZ; DARIDO, 2015).

Identificamos que, na Base Nacional Comum Curricular (BNCC) (BRASIL, 2017), ao lado da música, do teatro e das brincadeiras de faz de conta, a dança possibilita que as crianças se comuniquem e se expressem no entrelaçamento entre corpo, emoção e linguagem. Essa perspectiva vai ao encontro do que está posto nas Diretrizes Curriculares para a Educação Infantil (DCNEIs) (BRASIL, 2010), para a qual a proposta pedagógica das instituições deve garantir que elas cumpram sua função sociopolítica e pedagógica com o "[...] rompimento de relações de dominação etária, socioeconômica, étnico-racial, de gênero, regional, linguística e religiosa" (BRASIL, 2010, p. 17), bem como a apropriação pelas crianças das contribuições “[...] histórico-culturais dos povos indígenas, afrodescendentes, asiáticos, europeus e de outros países da América” (BRASIL, 2010, p. 19).

A fim de dialogar com essas orientações, torna-se imprescindível abandonar os currículos construídos por conceitos universais, que se julgam capazes de abarcar toda e qualquer realidade. Para Ponce e Araújo (2019), a democratização de conhecimentos e epistemologias é um caminho possível para estabelecermos inteligibilidade entre os vários saberes, a serem considerados em relações horizontais.

Nesse contexto, acreditamos no potencial das danças populares como veículo e objeto da cultura, que é plural, produto cultural disponível para que os praticantes - professores e crianças - possam fazer diferentes usos no fazer cotidiano. Compreender essas manifestações, em seus aspectos identitários, histórias, brincadeiras, ludicidade, personagens, expressões corporais e músicas, possibilita articular diferentes linguagens (corporal, musical, artística, oral) e campos de conhecimento (EF, Artes, Música, Pedagogia) e, como consequência, fortalecer a formação das crianças para a diversidade. Metodologicamente, podem proporcionar experiências de aprendizagem que perpassem a brincadeira, pautadas na liberdade de expressão e entendendo as crianças como produtoras de cultura.

As orientações pedagógicas para produção de experiências pautadas na diversidade cultural, que considere a criança como protagonista de suas aprendizagens, perpassa pela subjetividade e intencionalidade dos professores, pois eles possuem maneiras singulares ensinar. Nessa investigação, o entendimento de consumo produtivo (CERTEAU, 1994) torna-se elementar, pois os usuários não recebem, de forma passiva, aquilo que lhe é imposto 
e, assim, a cultura se manifesta nos usos e nas apropriações que os praticantes fazem de produtos culturais que lhes são oferecidos, pois:

\begin{abstract}
Na realidade, diante de uma produção racionalizada, expansionista, centralizada, espetacular e barulhenta, poste-se uma produção de tipo totalmente diverso, qualificada como 'consumo', que tem como características suas astúcias, seu esfarelamento em conformidade com as ocasiões, sua 'pirataria', sua clandestinidade, seu murmúrio incansável, em suma, uma quase-invisibilidade, pois ela quase não se faz notar por produtos próprios (onde teria o seu lugar?), mas por uma arte de utilizar aqueles que lhe são impostos (CERTEAU, 1994, p. 94).
\end{abstract}

Diante do exposto, anunciamos a necessidade de compreensão sobre como tem sido o trabalho pedagógico com as danças populares nas instituições infantis, refletindo sobre suas possibilidades e os enfrentamentos quanto à natureza epistemológica e à dinâmica curricular dessa primeira etapa da escolarização. Este estudo tem como objetivo analisar os usos e apropriações que os dinamizadores de Artes e EF fazem das danças populares na EI de Vitória/ES.

\title{
METODOLOGIA
}

Trata-se de uma investigação qualitativa, de caráter exploratório, com produção de um diagnóstico sobre os usos das danças populares no campo delimitado. Utiliza, como método, a pesquisa descritivo-interpretativa, que é descritiva, pois tem propósito de alcançar melhor compreensão da situação presente, e interpretativa, pela intenção de classificar e conceituar informações (THOMAS; NELSON; SILVERMAN, 2007). As análises tiveram, como ponto de partida, uma categorização referente aos dois blocos de perguntas, e a construção do texto se deu no cruzamento e nas interpretações das respostas dos participantes, destacando os pontos de maior recorrência.

O questionário foi produzido com auxílio do Google Forms ${ }^{4}$, composto por 25 perguntas, divididas nos blocos: a) perfil profissional: com dados de formação e tempo de atuação na rede de Vitória, experiências/vivências com a dança fora do espaço de mediação nos CMEIs e; b) as possibilidades e os desafios da abordagem das danças populares na EI. Neste artigo, analisamos as respostas referentes às perguntas apresentadas no Quadro 1:

\footnotetext{
${ }^{4}$ Ferramenta gratuita para criar formulários online. Possibilita produzir pesquisas de múltipla escolha, fazer questões discursivas, solicitar avaliações em escala numérica, entre outras opções.
} 
Quadro 1. Perguntas do questionário

\begin{tabular}{|c|c|}
\hline Perfil profissional & $\begin{array}{l}\text { Possibilidades e os desafios da abordagem das } \\
\text { danças populares na EI }\end{array}$ \\
\hline $\begin{array}{l}\text { 1. Área de formação? } \\
\text { 2. Possui Pós-graduação? } \\
\text { 3. Há quanto tempo você atua na rede municipal de } \\
\text { EI de Vitória? } \\
\text { 4. Você possui experiências/vivências com a dança } \\
\text { em espaços não escolares? Se sim, comente um } \\
\text { pouco sobre essas experiências/vivências. }\end{array}$ & $\begin{array}{l}\text { 5. Você considera relevante abordar as danças } \\
\text { populares na EI? } \\
\text { 6. Você já utilizou as danças populares em suas aulas } \\
\text { no CMEI? Comente um pouco sobre o seu trabalho } \\
\text { com as danças populares. } \\
\text { 7. Você já teve o desejo de trabalhar com as danças } \\
\text { populares, mas, por algum motivo, esse desejo não } \\
\text { se concretizou? Comente sobre isso. } \\
\text { 8. Em geral, as danças populares estão presentes no } \\
\text { cotidiano do CMEI que você trabalha? Se sim, em } \\
\text { que momentos elas aparecem? } \\
\text { 9. Você se considera apta (apto) para trabalhar com } \\
\text { as danças populares na EI? } \\
\text { 10. Em sua opinião, quais são os principais desafios } \\
\text { para a abordagem das danças populares na EI? } \\
\text { 11. Você tem interesse em participar de uma } \\
\text { formação sobre as danças populares com a EI? }\end{array}$ \\
\hline
\end{tabular}

Fonte: Os autores.

Enviamos, por e-mail, aos 49 CMEIs, da rede de municipal de Vitória, o convite para participação na pesquisa. Por este canal de comunicação, os diretores das unidades de ensino disponibilizaram os contatos dos dinamizadores e, assim, encaminhamos o questionário. Após circular durante um mês, obtivemos respostas de 24 dinamizadores de Artes e EF, amostra que corresponde a $10 \%$ do total de profissionais que exercem a função neste segmento. A opção pelos dinamizadores se justifica por serem os professores com formação específica para o ensino sistematizado das danças como objeto de intervenção da cultura corporal e/ou artística. Esta pesquisa foi aprovada no Comitê de Ética em Pesquisa da Universidade Federal do Espírito Santo, sob o Parecer n ${ }^{\circ}$. 4.372.283/2020.

Considerando os limites deste artigo, apresentaremos, de forma breve, o perfil profissional dos participantes e, na sequência, as análises e discussões relacionadas aos usos que os professores dizem fazer das danças populares em seus contextos de atuação pedagógica.

\section{ANÁLISES E DISCUSSÃO}

A maioria (19) dos dinamizadores é licenciada em EF, quatro são em Artes Visuais e uma possui licenciatura em Música. Parte significativa possui um ou mais cursos de pósgraduação na área da EF, Ensino da Dança e da Educação em geral, e, apenas, três não possuem nenhuma pós-graduação. Dos participantes, 15 possuem dez anos ou mais de experiência nesse segmento. Metade dos professores (12) teve experiências com a dança 
em espaços não escolares, seja como praticante de dança, na participação de cursos/formações, seja mesmo como apreciador de espetáculos.

Entendemos que os conhecimentos relacionados à cultura popular devem ser compreendidos em seus usos. Nesse caso, nos interessou mapear as maneiras singulares de mediação, praticadas pelos dinamizadores. A cultura popular, aqui entendida na perspectiva de Certeau (1994), é aquela produzida pelo homem comum em suas diferentes maneiras e artes de fazer o cotidiano.

As danças populares podem se configurar como manifestações potentes para que as crianças experimentem diferentes ritmos, que contam sobre a cultura, identidade e história de um determinado grupo, “[...] abarcam não somente manifestações tidas como tradicionais, a exemplo do congado, maracatu, bumba meu boi, frevo, mas também aquelas que ganham forma no meio urbano" (GUARATO, 2014, p. 66). Elas necessitam de sistematização para atender às necessidades de aprendizagem e desenvolvimento das crianças e à dinâmica curricular dos CMEIs, a qual não se organiza de maneira disciplinar, mas na articulação de diferentes campos de conhecimentos.

Dentre os usos que os dinamizadores dizem fazer das danças populares na EI, destacamos algumas possibilidades e determinados fatores que dificultam sua abordagem. Dos participantes, 19 afirmam que já utilizaram dessas danças em suas aulas, e 5 nunca abordaram. No Quadro 2, podemos observar que foram relacionados 26 tipos de manifestações diferentes:

Quadro 2. Danças populares utilizadas

\begin{tabular}{|c|c|c|c|}
\hline Dança & Recorrência & Dança & Recorrência \\
\hline Congo & 12 & Quadrilha & 2 \\
\hline Samba & 8 & Forró & 2 \\
\hline Carimbó & 6 & Pau de fita & 2 \\
\hline \multirow{4}{*}{$\begin{array}{l}\text { Cirandas } \\
\text { Danças de roda } \\
\text { Cantiga de roda } \\
\text { Brincadeira cantada }\end{array}$} & 3 & \multirow{4}{*}{ Maracatu } & \multirow{4}{*}{2} \\
\hline & 1 & & \\
\hline & 1 & & \\
\hline & 1 & & \\
\hline \multirow{2}{*}{ Jongo } & \multirow[t]{2}{*}{4} & \multirow{2}{*}{$\begin{array}{l}\text { Indígenas } \\
\text { Nação Tupi-guarani }\end{array}$} & 1 \\
\hline & & & 1 \\
\hline Frevo & 4 & Afro & 1 \\
\hline Maculelê & 3 & Catira & 1 \\
\hline Dança do Coco & 3 & Congada & 1 \\
\hline Capoeira & 3 & Country & 1 \\
\hline \multirow{3}{*}{$\begin{array}{l}\text { Boi Pintadinho } \\
\text { Bumba-meu-Boi } \\
\text { Boi de Goiabeiras }\end{array}$} & 1 & \multirow{3}{*}{ Reisado } & \multirow[t]{3}{*}{1} \\
\hline & 1 & & \\
\hline & 1 & & \\
\hline Hip hop & 2 & Samba de roda & 1 \\
\hline
\end{tabular}




\begin{tabular}{|l|c|l|}
\hline Dança de rua & 1 & \\
\hline \multicolumn{3}{c|}{ Fonte: Os autores. } \\
\hline
\end{tabular}

As danças e cantigas de roda, cirandas e brincadeiras cantadas possuem destaque no cotidiano dos CMEIs, porém se diferenciam por seu uso de forma mais contínua, nas mediações ao longo de todo o ano, principalmente, por envolverem aspectos lúdicos: a brincadeira, as rimas, a imaginação, a contação de histórias e a diversão. A Professora 4, dinamizadora de EF, nos traz que:

\begin{abstract}
$\mathrm{Na}$ EI, as atividades com dança são permeadas por elementos capazes, por si só, de produzirem encantamento nas crianças, tais como a ludicidade, a musicalidade, o movimento, a socialização. Destaca-se que a possibilidade da multiplicidade de linguagens, que é tão enriquecedora e peculiar na EI, deve estar presente no currículo, de modo que na tessitura das experimentações, as diversas formas de expressão são vivenciadas em si mesmas, ao passo que disparam outras formas de expressão.
\end{abstract}

Para o Professor 24, dinamizador de EF, a brincadeira é fundamental na inserção das danças de maneira geral, na EI, pois, segundo ele, "brincamos de dançar com várias músicas infantis, com coreografias ou apenas explorando as várias possibilidades de expressão corporal com a música". Essa abordagem se aproxima da perspectiva apresentada nas DCNEIs (BRASIL, 2010), para as quais a brincadeira é eixo para as práticas pedagógicas com as crianças nas instituições infantis.

Destacamos a expressiva abordagem das manifestações capixabas, especialmente, o congo, também o jongo e o Boi de Goiabeiras. Segundo Brasileiro (2010), as danças do universo popular são uma forma de valorizar a cultura regional, e os professores corroboram com essa afirmação, apontando a possibilidade de aproximação da criança com a cultura local, como uma especificidade da dança de cunho popular, conforme pontua a Professora 8, dinamizadora de EF:

Começamos o projeto a partir da cultura do bairro, ampliamos para município de Vitória, estado do ES e Brasil. Durante esses anos, dei ênfase nas danças populares principalmente para o congo, momentos de muita riqueza cultura para nossas crianças.

Segundo os professores, essas danças são abordadas nas aulas, nas atividades lúdicas de maneira geral, mas afirmam que são mais recorrentes em datas comemorativas, eventos para as famílias, apresentações e festas culturais. Rodrigues (2015) destaca que o uso das danças, em eventos pontuais, pode promover uma experiência negativa para crianças menos hábeis ao enfatizar a mecanização de gestos e repetições. Em relação a essa abordagem em 
momentos específicos, a Professora 9, que é dinamizadora de EF, percebe que as danças aparecem de forma estereotipada: “[...] a dança não é vista como um importante conteúdo de aprendizado e sim como uma forma de apresentar o que adulto deseja mostrar".

Essa perspectiva remete a uma concepção de infância que desconsidera o protagonismo e as agências das crianças e, ao tratar as danças populares em momentos pontuais, coloca-se a centralidade no produto, ao invés de valorizar o processo, que é onde acreditamos que aconteçam as aprendizagens mais significativas, pois:

[...] a criança, centro do planejamento curricular, é sujeito histórico e de direitos que se desenvolve nas interações, relações e práticas cotidianas a ela disponibilizadas e por ela estabelecidas com adultos e crianças de diferentes idades nos grupos e contextos culturais nos quais se insere. Nessas condições ela faz amizades, brinca com água ou terra, faz-de-conta, deseja, aprende, observa, conversa, experimenta, questiona, constrói sentidos sobre o mundo e suas identidades pessoal e coletiva, produzindo cultura (BRASIL, 2010, Art. $4^{\circ}$ ).

É necessário desnaturalizar esse modelo de "apresentações", que, muitas vezes, expõem as crianças a uma experiência constrangedora ao reproduzirem gestos inventados por adultos. Não estamos, com isso, desconsiderando a importância dos eventos artísticos e culturais que envolvem as crianças e famílias, entretanto entendemos a necessidade de ressignificação desses momentos, para que, de fato, representem as criações infantis.

Apesar de terem uma visibilidade maior nos momentos festivos, a maioria dos professores relatou que o trabalho com as danças populares esteve inserido nos projetos institucionais, estabelecendo uma articulação curricular entre áreas de conhecimento e profissionais que atuam na instituição. Sabemos que as mediações pedagógicas norteadas por projetos é uma prática recorrente nos CMEIs de Vitória (ZANDOMIÍNEGUE; MARTINS; MELLO, 2020). Possibilitam a contextualização e potencializam a produção de experiências e aprendizagens com as crianças, de forma que práticas e sujeitos dialogam entre si. A Professora 4 exemplifica as diferentes temáticas que utilizou nessas danças:

Ocorreram em minhas aulas sempre desenvolvemos um trabalho que estivesse dentro da proposta de institucional da escola e ao mesmo tempo conseguisse trabalhar as diversas possibilidades da EF Escolar [...] A dança na EI, como conteúdo que possui características próprias, mas que também engloba outros conteúdos e a nossa proposta com a dança foi de trabalhar a ludicidade, o ritmo, a percepção corporal e conhecimento seja histórico, (Como no Projeto "De onde vem os Ritmos Brasileiros)", literário (Como o Projeto "Girafas não sabem dançar"), geral como no trabalho (Projeto "Os esportes através da Dança”), em que alguns movimentos caraterísticos de práticas esportivas foram coreografados. 
Mello et al. (2018) defendem que os Projetos Institucionais são importantes mecanismos de articulação entre diferentes áreas do conhecimento e de sujeitos no âmbito da EI. As práticas pedagógicas passam a receber um tratamento integrativo, que favorece um trabalho coletivo que respeita as agências das crianças. Essa perspectiva contribui, inclusive, para que a EF e as Artes não sejam consideradas apêndices no contexto das unidades educativas da infância, encontrando espaços de diálogo com o trabalho com outras linguagens e saberes desenvolvidos pelas professoras regentes, com formação em Pedagogia.

Essa perspectiva é coerente com a dinâmica curricular da EI, a qual não se organiza de maneira fragmentada e disciplinar, mas de forma a articular diferentes áreas de conhecimento, práticas pedagógicas e praticantes. Nas DCNEIs (BRASIL, 2010, p. 12), temos que a organização curricular, nas instituições de EI, se caracteriza como:

Conjunto de práticas que buscam articular as experiências e os saberes das crianças com os conhecimentos que fazem parte do patrimônio cultural, artístico, ambiental, científico e tecnológico, de modo a promover o desenvolvimento integral de crianças de 0 a 5 anos de idade.

Observa-se que as experiências relativas ao patrimônio cultural e artístico possui destaque nas DCNEIs (BRASIL, 2010), e, dentre os usos e apropriações, uma das dinamizadoras destacou que as danças populares são importantes saberes para contemplar a temática étnico-racial, por meio das manifestações de origem africana, afro-brasileira e indígena. Segundo ela:

\footnotetext{
Essas danças são invisibilizadas e perdem sua origem ancestral. No meu entendimento as 'danças populares' fazem contraponto às 'eruditas'. O que é popular? O que é erudito? Uma materializa a outra, mas qual tem mais importância? De forma geral, existe uma valorização a tudo que vem de fora do Brasil, ou seja, o popular é menos valorizado. Dentro da temática étnico-racial o trabalho com as danças de origem africana, afro-brasileira e indígena, na EI, representam a história, cultura e pertencimento de parte da maioria da população brasileira. Essas danças representam resistências e histórias negadas historicamente no processo educacional. Considero de extrema importância o trabalho com esse significado na EI (PROFESSORA 9).
}

Na fala da Professora 9, percebemos a ideia de que os conhecimentos provenientes das camadas populares foram historicamente invisibilizados, resultado de uma relação epistemológica hierarquizada. Santos (2010) afirma que os conhecimentos populares, leigos, plebeus, camponeses ou indígenas desaparecem como conhecimentos relevantes, por se encontrarem além do universo do verdadeiro e do falso, resultado da lógica binária da ciência moderna. Para Santos (2007, p. 24): 
[...] o mais preocupante no mundo de hoje é que tanta experiência social fique desperdiçada, porque ocorre em lugares remotos. Experiências muito locais, não muito conhecidas nem legitimadas pelas ciências sociais hegemônicas, são hostilizadas pelos meios de comunicação social, e por isso têm permanecido invisíveis, 'desacreditadas'.

No contexto da EI, para efetivação de seus objetivos, as propostas pedagógicas dessas instituições deverão prever condições para o trabalho coletivo e para a organização de materiais, espaços e tempos que assegurem, dentre outros aspectos: “[...] a apropriação pelas crianças das contribuições histórico-culturais dos povos indígenas, afrodescendentes, asiáticos, europeus e de outros países da América" (BRASIL, 2010, p. 20). Segundo a Professora 18, que é dinamizadora de Artes, e a Professora 21, dinamizadora de EF, a abordagem das danças populares ocorre:

[...] sempre, todos os anos, não somente pela linguagem da arte, mas como caminho etnográfico e estético proposto pela lei 10.639/03 [história da cultura afro-brasileira e africana] e 11.645/08 [história da cultura afro-brasileira, africana e indígena] (PROFESSORA 18).

Trabalhamos as culturas africana e indígena durante um momento do nosso projeto institucional e enquanto as professoras de sala trabalhavam com hábitos, comidas, vestimentas, eu trabalhei a questão da cultura através da dança (PROFESSORA 21).

A BNCC, também, demarca a necessidade de proporcionar às crianças experiências que favoreçam o reconhecimento das diferenças, pois “[...] a instituição precisa conhecer e trabalhar com as culturas plurais, dialogando com a riqueza/diversidade cultural das famílias e da comunidade" (BRASIL, 2017, p. 37). Nesse sentido, entendemos que o termo "culturas plurais' indica um espaço de possibilidades para que as danças populares estejam inseridas nos cotidianos dessas instituições.

As reflexões sobre os conhecimentos da cultura popular, no currículo escolar, sugerem uma ruptura com o modelo de educação que, pautado no discurso acadêmicocientífico, tem menosprezado os saberes populares. O desenvolvimento de processos educativos que sistematizem e socializem as culturas historicamente produzidas são imprescindíveis para o exercício da função social e desafia a escola a ser um espaço de promoção de diálogo entre os diferentes saberes: científico, popular, escolar. Zandomínigue e Mello (2014, p. 23) destacam:

[...] a necessidade de formulação de políticas públicas na educação destinadas a superar o modelo padrão e uniforme de ensino, em um contexto social complexo e multifacetado, no qual as escolas estão inseridas, em uma sociedade marcada por profundas diferenças sociais, econômicas e culturais. O modelo de escola 
predominante na sociedade brasileira afirma um ideal cultural ocidental e eurocêntrico de educação, negligenciando ou se omitindo diante das relações de poder que perpassam pelas diferenças culturais presentes no contexto nacional.

As danças populares são apropriadas, nos dizeres de Certeau (1994), como movimento tático ${ }^{5}$, de resistência a uma lógica epistemológica estratégica ${ }^{6}$ e, quando analisamos os principais desafios nos usos das danças populares, pontuados pelos professores, identificamos que as questões relacionadas à diversidade étnico-racial são realmente recorrentes. Associadas a elas, desponta o tema da religião, como pontua a Professora 8, com os resultados do seu Trabalho de Conclusão da pós-graduação em Ensino da dança:

Observei que a questão religiosa é a maior barreira a ser rompida naquele espaço onde a pesquisa foi realizada. Mediante relatos de professores e famílias, pude perceber que o preconceito existe principalmente nas danças de origem africana.

Com esse relato, entendemos que a dificuldade de aceitação das danças populares não tem a ver apenas com as religiões, mas, sobretudo, com aquilo que as famílias acreditam estar relacionado à cultura africana e afro-brasileira. De fato, muitas danças locais acontecem em momentos de festas religiosas e possuem uma musicalidade diferente daquelas que as crianças têm familiaridade nas igrejas e em suas casas. O barulho, o emaranhado de instrumentos e o batuque são vistos como aspectos negativos e interpretados de modo pejorativo, como podemos observar no fragmento a seguir:

[...] já tentaram impedir a presença da dança com vários discursos, principalmente o religioso. Se for balé não tem problema nenhum, mas se for de origem africana, afro-brasileira ou indígena, essa dança será demonizada. Se a dança permitir a utilização de instrumentos musicais, o preconceito será ainda maior (PROFESSORA 9).

Como pudemos observar, mesmo com as tentativas de silenciar os conhecimentos populares na escola, eles continuam sendo abordados. Além da religiosidade, temos outros fatores dificultadores, apresentados no Gráfico 1:

\footnotetext{
${ }^{5}$ Movimento astucioso no espaço controlado pelo poder, representado pela estratégia. Para Certeau (1994, p. 100), a tática 'aproveita as ocasiões e delas depende'. O seu não lugar lhe permite mobilidade para se utilizar de falhas que se abrem na vigilância do poder.

${ }^{6}$ Manipulação das relações de forças, que se torna possível a partir do momento que um sujeito de querer e poder pode ser isolado. A estratégia postula um lugar que é a base de onde pode gerir as relações. É possível reconhecer, nessas estratégias, um tipo específico de saber, aquele que sustenta e determina o poder de conquistar para si um lugar próprio.
} 
Gráfico 1. Principais desafios

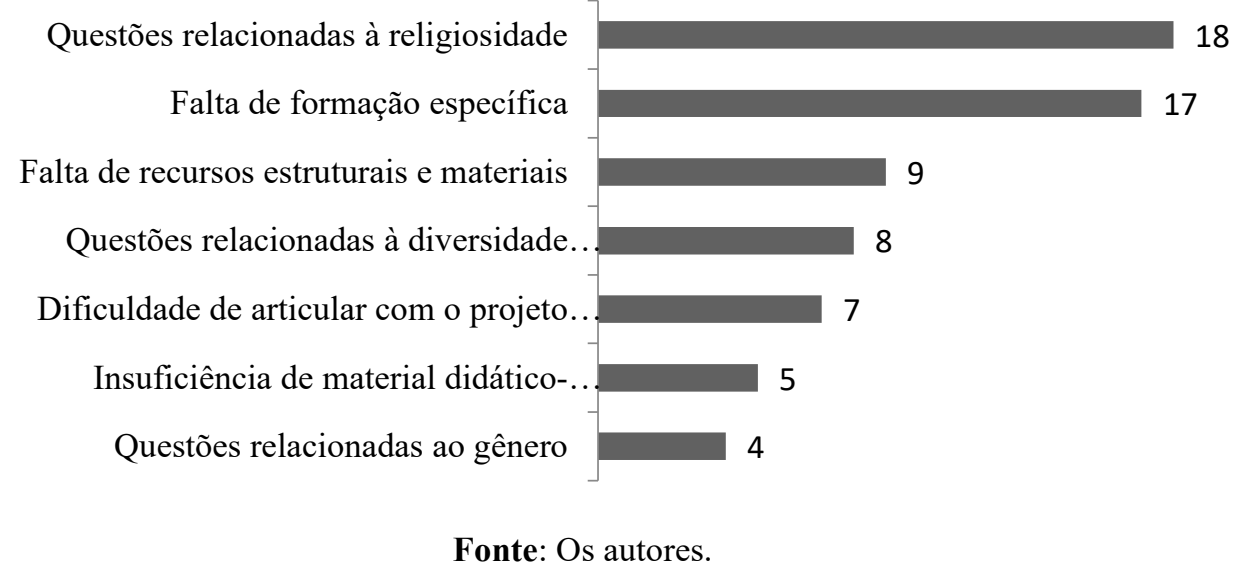

Observamos que a ausência de formação específica é o segundo fator que dificulta a mediação pedagógica com esse conhecimento. Pensando que as danças populares, no contexto da EI, não devem primar pelos movimentos estereotipados, pela performance corporal e pelos gestos coreografados, cabe indagar: até que ponto é necessária uma formação tão específica para se trabalhar dança na EI? Que tipo de dança, no contexto do trabalho voltado para a cultura popular, exige dos docentes uma formação para além da formação inicial em EF, Artes e Música? Será que essa alegação é decorrente da falta de familiaridade e/ou de domínio corporal por parte dos docentes?

A falta de recursos materiais é um assunto recorrente quando se trata do ensino da $\mathrm{EF}$ nas escolas, muitas vezes, é justificativa para a sonegação de alguns conteúdos (CARVALHO; BARCELOS; MARTINS, 2020). Entendemos que, embora as vivências com as danças, na EI, devam ser abordadas como experimentações significativas para as crianças e menos como espetáculo coreografado, é necessária uma estrutura mínima para que as mediações aconteçam: piso adequado para que as crianças possam girar, rolar, saltar em segurança; um espaço arejado e protegido do sol; um aparelho de som e, se possível, instrumentos, principalmente, os percussivos. Consideramos que a utilização de materiais não estruturados, sobretudo, aqueles produzidos junto com as crianças, são "saídas" interessantes para incluir as danças populares no cotidiano escolar.

No Gráfico 1, chama-se a atenção que sete dinamizadores consideram difícil articular as danças populares com os projetos institucionais dos CMEIs, informação que vai de encontro com as respostas dadas por eles, quando perguntados se, nas mediações com essas 
manifestações, foram realizadas em consonância com os projetos. Entendemos que, mesmo reconhecida, essa dificuldade não inviabilizou que as danças fossem trabalhadas dentro dos projetos.

A carência de materiais didático-pedagógicos também foi sinalizada por cinco professores. Por um lado, entendemos que não cabe, na primeira etapa da Educação Básica, a lógica de adoção de livros didáticos clássicos para que o trabalho pedagógico se efetive. Por outro, concordamos que há necessidade de maior investimento em pesquisas que abordem essa temática de maneira propositiva e em estreita relação com as práticas docentes, com a escuta atenta e o reconhecimento das enunciações das crianças, de acordo com as especificidades da EI. Esse processo vem sendo instituído no contexto de Vitória, em formações continuadas construídas em parceria entre a secretaria de educação e a universidade, mediadas pelo Núcleo de Aprendizagens com as Infâncias e seus Fazeres (NAIF).

As questões relacionadas ao gênero aparecem em menor quantidade. Os relatos docentes denotam que há um receio por parte dos dinamizadores em criar embates com os responsáveis pelas crianças. O Professor 12 reforça que as questões de gênero "[ [...] já se apresentam muito forte nas crianças e há uma resistência das famílias quando nos referimos aos meninos e a dança”. Leal et al. (2017) ressaltam o papel da escola em desconstruir comportamentos discriminatórios em diálogo com as famílias. Com efeito, colaborar com a formação dos adultos responsáveis pelas crianças que visa superar os estigmas que determinam o que é próprio para meninos e meninas. Para as autoras, as crianças têm o direito de vivenciarem práticas corporais sem amarras classificatórias de qualquer natureza.

Os dados examinados, neste artigo, oferecem pistas para entendermos o porquê as danças populares não são abordadas de maneira contínua e aprofundadas nas mediações. Com isso, ‘empurrando' seus usos em momentos festivos, pois, segundo Brasileiro (2010), nas apresentações, elas recebem uma "visibilidade temporária", pois, nesses momentos, são vistas e ganham uma "roupagem adequada e higienizada [...]" (BRASILEIRO, 2010, p. 148). Talvez, pelo receio dos professores em não conseguir desvincular essas danças populares de suas características peculiares (ocorrência em festas religiosas, de origem africana e indígena). Seriam questões sensíveis para o professor trabalhar. Entretanto, na prerrogativa dos usos, podemos consumir e ressignificar as danças, seus aspectos potentes para proporcionar experiências sensoriais, rítmicas, cognitivas, artísticas, dramáticas 
significativas, autorais, criativas e diversificadas para as crianças. Além disso, do ponto de vista pedagógico, o que nos interessa das danças populares são suas características como manifestações culturais, como patrimônio imaterial que constitui povo brasileiro, sem a intenção de doutrinação religiosa.

\section{CONSIDERAÇÕES FINAIS}

Após interpretação dos resultados, apresentamos algumas considerações deste diagnóstico sobre as danças populares no contexto estudado. Observamos que os professores fazem diferentes usos das danças populares. Além de abordarem ritmos variados, apropriamse delas para inserirem as crianças na cultura local, contextualizando as manifestações populares que ocorrem nos bairros da Grande Vitória. Identificamos que as danças, cantigas, cirandas e brincadeiras de roda são utilizadas de maneira recorrente, perpassando diferentes práticas ao longo do ano letivo, principalmente, por suas características lúdicas e brincantes. Mesmo assim, ponderamos que a centralidade da criança e seu protagonismo, neste processo, ainda se apresentam de maneira superficial, sendo uma lacuna a ser considerada.

Ressaltamos que alguns professores consideram difícil estabelecer a articulação das danças populares com os projetos institucionais dos CMEIs, porém essa dificuldade não impossibilitou que as mediações acontecem na relação entre diferentes áreas e profissionais que atuam colaborativamente, uma dinâmica própria da EI. Embora estejam associadas aos projetos, estas danças têm uma importância e visibilidade maior nos momentos festivos, como em apresentações. Este dado pode estar relacionado à concepção de infância, que diverge da ideia da criança com produtora de cultura e protagonista de suas próprias aprendizagens, transformando esse momento de espetáculo em experiências sem sentido e, muitas vezes, constrangedoras para as crianças.

Ao mesmo tempo em que as danças populares são consideradas conhecimentos importantes e utilizadas pelos professores para inserir o debate étnico-racial nas instituições infantis, percebemos que é um tema sensível. Pelas respostas, vimos que a barreira étnicoracial está muito associada à questão religiosa, entende-se que há uma resistência das famílias em aceitar danças que tenham alguma semelhança ou relação com outras culturas, sobretudo, a africana. Além desses desafios, os professores apontaram, também, a necessidade de formação específica, mais recursos materiais e aporte didático-pedagógico. Todos estes pontos podem indicar o porquê de essas danças ocuparem o lugar das festas e terem pouca 
continuidade e aprofundamento na produção de experiências de aprendizagem com as crianças.

\section{REFERÊNCIAS}

BRASIL. Secretaria de Educação Básica. Diretrizes curriculares nacionais para a educação infantil. Brasília: MEC, SEB, 2010.

. Ministério da Educação. Secretaria de Educação Básica. Base Nacional Comum Curricular. Brasília, DF: MEC/SEB, 2017.

BRASILEIRO, Lívia Tenório. A dança é uma manifestação artística que tem presença marcante na cultura popular brasileira. Pró-posições, Campinas/SP, v. 21, n. 3, p. 135-153, set./dez. 2010.

CARVALHO, João Paulo Ximenes; BARCELOS, Marciel; MARTINS, Rodrigo Lema Del Rio. Infraestrutura escolar e recursos materiais: desafios para a educação física

contemporânea. Revista Humanidades \& Inovação, Palmas, n, 4. v, 7. p. 1-25, abr. 2020.

CERTEAU, Michel de. A invenção do cotidiano. Artes de fazer, Petrópolis: Vozes, 1994.

DINIZ, Irlla Karla dos Santos; DARIDO, Suraya Cristina. Blog educacional e o ensino das danças folclóricas nas aulas de educação física: aproximações a partir do currículo do estado de São Paulo. Movimento, Porto Alegre, v. 21, n. 3, p. 701-716, 2015.

GEHRES, Adriana de Faria. As danças nas escolas: uma travessia entre os contextos e as experiências. Pensar a Prática, Goiânia, v. 23, 2020.

GUARATO, Rafael. Por um conceito de danças populares. Dança, Salvador, v. 3, n. 1, p. 61-74, 2014.

LEAL, Nathalia Costa et al. A questão de gênero no contexto escolar. Leopoldianum, Santos/SP, v. 43, n. 121, p. 95-104, jul./dez. 2017.

MELLO, André da Silva et al. Educação física na educação infantil: do isolamento pedagógico à articulação com outras áreas do conhecimento. Kinesis, Santa Maria/RS, v. 36, n. 3, p. 15-27, set./dez. 2018.

PONCE, Jurema Branca; ARAÚJO, Wesley. A justiça curricular em tempos de implementação da BNCC e de desprezo pelo PNE (2014-2024). Revista e-Curriculum, São Paulo, v. 17, n. 3, p. 1045-1074, 2019.

RODRIGUES, Renata Marques. Conhecendo o mundo na escola: uma intervenção com a dança na educação infantil. Cadernos de formação RBCE, n. 1, p. 80-90, 2015.

SANTOS, Boaventura de Sousa. Renovar a teoria crítica e reinventar a emancipação social. São Paulo: Boitempo, 2007. 
. Para além do pensamento abissal: das linhas globais a uma ecologia de saberes. In: SANTOS, Boaventura de Sousa; MENESES, Maria Paula (org.). Epistemologias do Sul. São Paulo: Cortez, 2010. p. 31-83.

THOMAS, Jerry R.; NELSON, Jack K.; SILVERMAN, Stephen J. Métodos de pesquisa em atividade física. 5. ed. Porto Alegre: Artmed, 2007.

ZANDOMÍNEGUE, Bethânia Alves Costa; MELLO, André da Silva. A cultura popular nas aulas de educação física. Curitiba: Appris, 2014.

ZANDOMIÍNEGUE, Bethânia Alves Costa; MARTINS, Rodrigo Lema Del Rio; MELLO, André da Silva. A educação física na articulação curricular com a educação infantil.

Revista Brasileira de Educação Física Escolar, São Paulo, Ano V, v. 3, p. 100-118, mar. 2020. 